\title{
Evaluation of the effect of chickenpox vaccination on shingles epidemiology using agent-based modeling
}

\author{
Ellen Rafferty ${ }^{1}$, Wade McDonald ${ }^{2}$, Weicheng Qian ${ }^{2}$, Nathaniel D Osgood ${ }^{2}$, Alexander Doroshenko ${ }^{\text {Corresp. }}{ }^{3}$ \\ ${ }^{1}$ School of Public Health, University of Saskatchewan, Saskatoon, Saskatchewan, Canada \\ 2 Department of Computer Science, University of Saskatchewan, Saskatoon, Saskatchewan, Canada \\ 3 Faculty of Medicine and Dentistry, Department of Medicine, Division of Preventive Medicine, University of Alberta, Edmonton, Alberta, Canada \\ Corresponding Author: Alexander Doroshenko \\ Email address: adoroshe@ualberta.ca
}

Background. Biological interactions between varicella (chickenpox) and herpes zoster (shingles), two diseases caused by the varicella zoster virus (VZV), continue to be debated including the potential effect on shingles cases following the introduction of universal childhood chickenpox vaccination programs. We investigated how chickenpox vaccination in Alberta impacts the incidence and age-distribution of shingles over 75 years postvaccination taking into consideration a variety of plausible theories of waning and boosting of immunity. Methods. We developed an agent-based model representing VZV disease, transmission, vaccination states and coverage, waning and boosting of immunity in a stylized geographic area, utilizing a distance-based network. We derived parameters from literature, including modeling, epidemiological, and immunology studies. We calibrated our model to the age-specific incidence of shingles and chickenpox prior to vaccination to derive optimal combinations of duration of boosting and waning of immunity. We conducted paired simulations with and without implementing chickenpox vaccination. We computed the count and cumulative incidence rate of shingles cases at 10, 25, 50 and 75 years intervals, following introduction of vaccination, and compared the difference between runs with vaccination and without vaccination using Mann-Whitney U-test to determine statistical significance. We carried out sensitivity analyses by increasing and lowering vaccination coverage and removing biological effect of boosting. Results. Chickenpox vaccination led to a decrease in chickenpox cases. The cumulative incidence of chickenpox had dropped from 1,254 cases per 100,000 person-years pre-chickenpoxvaccination to 193 cases per 100,000 person-years 10 years after the vaccine implementation. We observed an increase in the all-ages shingles cumulative incidence at 10 and 25 years post chickenpox vaccination and mixed cumulative incidence change at 50 and 75 years post-vaccination. The magnitude of change was sensitive to duration of boosting and ranged from an increase of 22 to 100 per 100,000 person-years at 10 years 
post-vaccination for 2 and 7 years of boosting respectively $(p<0.001)$. At 75 years postvaccination, cumulative incidence ranged from a decline of 70 to an increase of 71 per 100,000 person-years for 2 and 7 years of boosting respectively $(p<0.001)$. Sensitivity analyses had a minimal impact on our inferences except for removing effect of boosting. Discussion. Our model demonstrates that over the longer time period, there will be a reduction in shingles incidence driven by the depletion of source of shingles reactivation; however in the short to medium term some age cohorts may experience an increase in shingles incidence. Our model offers a platform to further explore the relationship between chickenpox and shingles, including analyzing the impact of different chickenpox vaccination schedules and cost-effectiveness studies. 
1 Evaluation of the effect of chickenpox vaccination on shingles epidemiology using agent-

2 based modeling.

3 Ellen Rafferty ${ }^{1}$, Wade McDonald ${ }^{2}$, Weicheng Qian ${ }^{2}$, Nathaniel D. Osgood ${ }^{2}$, Alexander

4 Doroshenko $^{3 *}$

$5 \quad{ }^{1}$ School of Public Health, University of Saskatchewan, Saskatoon, Canada

$6{ }^{2}$ Department of Computer Science Department, University of Saskatchewan, Saskatoon, Canada

$7{ }^{3}$ Faculty of Medicine and Dentistry, Department of Medicine, Division of Preventive Medicine,

8 University of Alberta, Edmonton, Canada

9

${ }^{*}$ Corresponding author: Alexander Doroshenko

11 E-mail address: adoroshe@ualberta.ca 


\section{ABSTRACT}

33 Background. Biological interactions between varicella (chickenpox) and herpes zoster

(shingles), two diseases caused by the varicella zoster virus (VZV), continue to be debated including the potential effect on shingles cases following the introduction of universal childhood chickenpox vaccination programs. We investigated how chickenpox vaccination in Alberta impacts the incidence and age-distribution of shingles over 75 years post-vaccination taking into consideration a variety of plausible theories of waning and boosting of immunity.

Methods. We developed an agent-based model representing VZV disease, transmission, vaccination states and coverage, waning and boosting of immunity in a stylized geographic area, utilizing a distance-based network. We derived parameters from literature, including modeling, epidemiological, and immunology studies. We calibrated our model to the age-specific incidence of shingles and chickenpox prior to vaccination to derive optimal combinations of duration of boosting and waning of immunity. We conducted paired simulations with and without implementing chickenpox vaccination. We computed the count and cumulative incidence rate of shingles cases at 10, 25, 50 and 75 years intervals, following introduction of vaccination, and compared the difference between runs with vaccination and without vaccination using MannWhitney U-test to determine statistical significance. We carried out sensitivity analyses by increasing and lowering vaccination coverage and removing biological effect of boosting. Results. Chickenpox vaccination led to a decrease in chickenpox cases. The cumulative incidence of chickenpox had dropped from 1,254 cases per 100,000 person-years prechickenpox-vaccination to 193 cases per 100,000 person-years 10 years after the vaccine implementation. We observed an increase in the all-ages shingles cumulative incidence at 10 and 25 years post chickenpox vaccination and mixed cumulative incidence change at 50 and 75 years post-vaccination. The magnitude of change was sensitive to duration of boosting and ranged from an increase of 22 to 100 per 100,000 person-years at 10 years post-vaccination for 2 and 7 years of boosting respectively $(p<0.001)$. At 75 years post-vaccination, cumulative incidence ranged from a decline of 70 to an increase of 71 per 100,000 person-years for 2 and 7 years of boosting respectively $(p<0.001)$. Sensitivity analyses had a minimal impact on our inferences except for removing effect of boosting.

Discussion. Our model demonstrates that over the longer time period, there will be a reduction in shingles incidence driven by the depletion of source of shingles reactivation, however in the 
63 short to medium term some age cohorts may experience an increase in shingles incidence. Our 64 model offers a platform to further explore the relationship between chickenpox and shingles, 65 including analyzing the impact of different chickenpox vaccination schedules and cost66 effectiveness studies.

67

68

69

71

72

73

74

75

76

77

78

79

80

81

82

83

84

85

86

87

88 
89

90 91

\section{INTRODUCTION}

Varicella (chickenpox) and herpes zoster (shingles) are two diseases caused by the varicella zoster virus (VZV). Individuals are generally infected with chickenpox in childhood. In Canada prior to vaccination, approximately 11.7 per 1,000 persons were infected with chickenpox each year, which was estimated to cost about 122 million CAD\$ annually. ${ }^{1}$ Following primary chickenpox infection, the VZV migrates to the sensory nerve ganglia, where it remains latent and can subsequently reactivate as shingles, which causes a dermatomal rash often accompanied by itching and pain. ${ }^{2}$ Shingles was estimated to occur at a rate of 1.2-3.4 per 1000 per year (3.9-11.8 cases per 1,000 per year in those $>65$ years) in Canada before chickenpox and shingles vaccination. ${ }^{3}$ Some studies suggest that the incidence of shingles has been increasing in the recent decades prior to the introduction of chickenpox vaccination. ${ }^{4-6}$

Although much remains unknown about shingles and the reactivation process, research has demonstrated that the maintenance of latency is largely governed by VZV cell-mediated immunity (VZV-CMI). Successful reactivation of shingles occurs when VZV-CMI weakens to a certain (unknown) level, which is often a result of the normal ageing process. ${ }^{7}$ However, the literature shows there are likely other risk factors that can result in inadequate immune response to VZV reactivation at any age, including mental health, stress, comorbid infections (e.g., cytomegalovirus $[\mathrm{CMV}]$ infection) and therapy, and disease-related immunosuppression (e.g., HIV-AIDS). ${ }^{7}$ In parallel to the natural waning of VZV-CMI immunity, one theory posits that exogenous boosting of VZV-CMI is a determinant of shingles reactivation. ${ }^{8-10}$ Exogenous boosting occurs when a VZV immune individual is exposed to a case of chickenpox or shingles.

The theory of exogenous VZV-CMI boosting has sparked a debate about whether the chickenpox vaccine will limit the boosting of immunity to shingles and therefore increase the incidence of the disease, however the empirical data to-date is largely inconclusive. ${ }^{4,11}$ This debate has prompted many countries, including the United Kingdom and France, to delay the implementation of a universal chickenpox vaccine, even though there is a safe and effective vaccine available. ${ }^{12}$ In comparison, other countries, including Canada and the USA, currently recommend a two-dose chickenpox vaccination schedule. ${ }^{13}$ Alberta introduced a universal onedose chickenpox vaccination program for 12-month-olds in 2002 and in 2012 added a second dose for children aged 4-6 years. Russell et al. found that shingles incidence was increasing in 
119 Alberta in the period 1994-2010, both before and after the introduction of the chickenpox 120 vaccination. ${ }^{4}$

121

122

123

124

125

126

127

128

129

130

131

132

133

134

135

136

137

138

139

140

141

142

143

144

145

146

147

The unique connection between chickenpox and shingles makes independently exploring their disease dynamics difficult. Using mathematical modeling to study the interacting factors related to these diseases - in particular, how chickenpox vaccination may impact shingles disease and epidemiology - complements conventional epidemiological studies and offers a unique approach to evaluating effects of vaccination in a controlled study using simulated data.

Most previous modeling studies of shingles and chickenpox have been conducted using aggregate population-level models. ${ }^{6}$ Both agent-based and aggregate models can simulate the indirect effects of varicella vaccination, including the changing risk of disease over time, herd immunity, age-category specific mixing and rates, and increasing age of infection. However, agent-based models (ABMs) provide a number of advantages in the study of many infectious diseases, including allowing the exploration and measurement of disease dynamics at multiple levels and the adjustment of both individual and population parameters. ${ }^{14-18}$ In the study of the VZV, ABMs can provide for realistic and comprehensive simulation of the transmission of infection and boosting of immunity by explicit modeling of network-mediated contacts, and flexibility in specifying interpersonal contact. ABMs allow the simulation of between-host dynamics (e.g., transmission) at an individual level, while also capturing spatial limits on such transmission and allowing the simulation of continuous within-host dynamics, including for both aging and individual waning of VZV-CMI; the characterization of such factors as continuous processes offers flexibility in terms of reporting and characterization of individual-level dynamics. ${ }^{15-17,19}$ ABMs can further represent detailed elements of vaccination, including vaccine attitudes, uncertainties in vaccine coverage and - critically for this study - continuous waning of vaccine immunity. Importantly for supporting options for later expansions and refinements of this model, the individual-level representation can readily depict reporting and vaccination attitudes dynamics based on family context. As ABMs support reporting an individual's disease or vaccination status in light of their history, catch-up immunization and breakthrough illness can also be represented in a modular manner that scales well to more complex vaccination regimes. Finally, ABMs take into account stochastics and readily accommodate large number of 
148 dimensions of heterogeneity, including sex, age, spatial location, comorbid conditions, and

149 detailed information on condition-specific individual history. ${ }^{16-19}$

150 A systematic review of empirical and modeling studies on the boosting of VZV-CMI for

151 shingles found that while there is evidence that boosting of VZV-CMI exists, there is little

152 evidence of the strength or duration of that boosting effect. ${ }^{6}$ The majority of chickenpox

153 vaccination models that incorporated boosting have predicted there will be an increase in

154 shingles incidence post chickenpox vaccination, however most of them have assumed a high

155 force of boosting. ${ }^{20-22}$ While modeling studies have explored the plausibility of various types of

156 boosting (e.g., progressive immunity, partial immunity, temporary immunity) ${ }^{22,23}$ there is little

157 exploration of the duration of boosting and the rate at which an individual's immunity to VZV

158 wanes over time, and how changing assumptions regarding these factors may impact the rate of

159 shingles following chickenpox vaccination.

Within this work, we sought to develop an ABM of chickenpox and shingles disease and

vaccination based on current immunological, medical and epidemiological data, and replicate the

epidemiology of chickenpox and shingles in Alberta, Canada before chickenpox vaccination. In Alberta, universal chickenpox vaccine has been in place since 2002, and detailed population demographics and chickenpox and shingles epidemiological data both before and after vaccine implementation were available. The primary objective of this study was to determine how chickenpox vaccination in Alberta impacts the incidence and age-distribution of shingles over 75 years post-vaccination taking into consideration a variety of plausible quantitative theories of waning and boosting of VZV immunity.

\section{METHODS}

We developed an ABM using the multi-method simulation software AnyLogic $®$ Professional (version 7.3.7), that represents chickenpox transmission, chickenpox and shingles disease and vaccination states, as well as the waning and boosting of VZV immunity (Data reference 1).

173 The model time unit is one year, however, the model operates in continuous time, where an event may occur at any arbitrary point in time, driven by either hazard rates (e.g., births, exposures), or by occurrence of other events (e.g., due to receipt of an "exposure" message sent by another agent) or at fixed time after occurrence of another event. The model is initialized after a 75-year

177 burn-in period, with any calibration or experimentation taking place after that period. We 
178 included such a burn-in period representing the average lifespan, to ensure that individuals were

179 at different stages of waning of VZV immunity and therefore at different risk of getting shingles.

180 This study was approved by the Health Ethics Research Board at the University of Alberta, study

181 ID Pro00068334.

182

183

Model structure and agent-characteristics

184 Statecharts related to within-host dynamics of the model are shown in Fig. 1A. A disease statechart where agents are in protected, susceptible or disease states determined an agents' probability of contracting chickenpox or shingles. The chickenpox and shingles vaccination schedules' statecharts represented which vaccination each agent received. The chickenpox vaccination schedule was modeled based on the Alberta VZV vaccination policy. ${ }^{24}$ Agents become due for chickenpox vaccines at the ages of 12 months for the first dose and at 4-6 years for the second dose (Fig. 1B). A representation of one-dose shingles vaccination given to individuals 50 years or older is depicted in the statechart shown in Fig. 1C, however currently shingles is not part of the publicly funded schedule in Alberta and therefore was not included as part of this analysis. An agent receives a vaccine dose with a probability based on its vaccine attitude as described below. If an agent receives the second dose but has not yet received the first, it may also receive a catch-up of the first dose with a certain probability. These probabilities are specified by parameters, as shown in Table 1. A demographic statechart represented Alberta births, ageing and mortality characteristics (Fig. 1D).

An agent's chance of being infected with chickenpox was dependent on whether they came into contact with someone with infection and the risk of transmission on such a contact. In comparison, an agent's likelihood of getting shingles was determined by their individual waning immunity timer (i.e., after chickenpox infection, a countdown on "Immunity Waning Time" initiates; when it completes, the agents become susceptible to shingles) as well as the number and degree of boosting they received. The immunity waning time was represented by a formula derived from Ogunjimi et al. ${ }^{25}$ and further by calibration (Fig. S1 \& Table 2). This equation inherits assumptions whereby force of reactivation is represented by a gamma distribution, initial CMI is represented by a normal distribution and the waning of immunity rate for shingles is a fixed rate that can be altered using a coefficient-waning of immunity coefficient (WoI). ${ }^{25}$ Furthermore, to account for the small but sharp increase in childhood shingles cases as observed 
209 in Russell et al. ${ }^{4}$, we included a small proportion of the population between the ages of 0 and 19

$210(5 \%)$ who had a short waning of immunity timer, allowing the model to account for individuals

211 who may have a weaker force of boosting, lower initial CMI (e.g., immunocompromised) or a

212 very quick waning of the immunity rate.

213 An agent's chance of getting shingles was determined by the number of years they were 214 protected through boosting. The model assumed progressive boosting, as postulated by Guzzeta 215 et $_{\text {al. }}{ }^{22}$ and therefore the number of years of boosting protection was calculated by multiplying 216 the number of times an agent comes into significant contact with the VZV by the duration in 217 years of each boosting event. The number of boosting events was determined through the 218 distance-based contact network and the duration of each boost was equal to the number of years 219 of added protection from shingles derived through each boost. Altering the quantitative values of 220 duration of boosting $(\mathrm{DoB})$ and $\mathrm{WoI}$ of shingles resulted in significant changes in the incidence 221 of shingles in a population.

\section{Contacts, network and spatial context}

223 The VZV model represented agents in a stylized geographic area, where agents are connected to other agents based on their proximity to one another (a distance-based network) (Fig. S2). When agents are randomly placed in the model environment they are connected to all other agents within their connection range (connectionRange_Norm). We included a low-density periphery and a higher density central region to better represent how disease spreads in a typical public health district in Alberta (or comparable jurisdiction) spanning an urban center and rural regions. Approximately $20 \%$ of our population were part of low density regions and the remainder; $80 \%$ resided in a high-density region. agents in a respective area per unit of distance in the model and along with the connectionRange determine the number of connections between agents. The contact rate (baseContactRate_Norm) determines the number of contacts (e.g., messages) an agent makes to a connected agent per day It is through these messages, sent through connections and contacts, that individuals can "transmit" chickenpox infection and provide boosting of VZV. To represent the increased contact time and range of connectivity among day-care and early school-aged children, we 
239 nine years were considered 'preferential contacts' in our model, and therefore have a higher

240 contact rate (baseContactRate_Pref) and connection range (connectionRange_Pref) when

241 interacting with individuals within the same age range. We chose this group to represent

242 'Preferential Contacts' as these are the age groups with the highest rates of chickenpox infection

243 as described by Kwong et al. ${ }^{27}$ These network adjustments ensured more realistic contact

244 network assumptions than those of random-mixing and compartmental models, such that not

245 only age-group preferences of contacts were captured, but also increased global connectivity due

246 to bridging effects of younger age groups was considered, both in a spatial context. To

247 characterize the transmissibility of VZV, we included a parameter whereby a susceptible agent

248 will have a certain probability of infection per contact message received from a normal

249 chickenpox case (probCPDiseaseOnContact), a breakthrough case of chickenpox

250 (probCPDiseaseOnContactWithBreakthrough) and a shingles infection

251 (probCPDiseaseOnContactWithShingles). The probability of infection in our model is dependent

252 on whether a susceptible agent would come in contact with and receive a message from an

253 infected case of chickenpox and shingles. For example, an infected agent in the preferred age

254 group (i.e., a child) may send 20 messages per day, each to a random connected agent.

255 Considering that the mean number of connections per agent in this age group is 10.87 , the

256 number of messages per connection-day equals to $20 / 10.87=1.8 \approx 1$ to 2 . Outside of the

257 preferred age group, this equates to $3 / 7.42=0.40<1$ message per connection-day (Table $1 \&$

258 Data Reference 1). Some of these messages do not lead to a receiving agent becoming infected

259 because the receiving agent is not susceptible, or an agent is not selected by a model to be

260 connected to an agent sending a message (not being part of contact pool). A complete age-

261 specific connection and contact frequency profile is available in Data Reference 2.

\section{Parameterization}

263 To parameterize the model, we conducted a comprehensive literature review of chickenpox and

264 shingles disease, including modeling, epidemiological, and immunology studies and drew

265 evidence from Alberta's Interactive Health Data Application (IHDA). ${ }^{28}$ The main parameters are

266 listed in Table 1. We drew demographic data, including Alberta life tables, and population and

267 age distributions, and Canadian fertility rates from Statistics Canada. ${ }^{29-31}$ Chickenpox

268 vaccination parameters, such as those associated with primary vaccine failure and waning of

269 vaccination immunity were derived from literature. ${ }^{32-34}$ We built the mechanism whereby 
270

271

272

273

274

275

276

277

278

279

280

281

282

283

284

285

286

287

288

289

290

291

292

293

294

295

296

297

298

299

300

vaccine coverage was generated by our model based on distribution of vaccination probabilities and population vaccination attitudes as described by Doroshenko et al. ${ }^{35}$ We classified all individuals into three groups: those who accept, reject and are hesitant to receive vaccination, and we assigned vaccination probabilities for each of these groups. We used calibration to ensure that model-generated vaccine coverage rates were comparable to those reported in Alberta. ${ }^{28}$ For the baseline scenario in the main experiment, chickenpox vaccination maintained an average coverage for the first dose of $85.58 \%$ (95\% CI 85.54-85.62) and second dose coverage of $80.28 \%$ (95\% CI 80.24-80.32) across all years and all model runs.

\section{Calibration and validation of the model}

We calibrated our model using a step-wise approach.

First, contact and mixing patterns, as well as the probability of infection per contact message, were determined using a pattern-oriented modeling approach. Pattern-oriented modeling involves identifying multiple patterns of behaviour in a complex system and constructing model structures and parameters that replicate those patterns. ${ }^{36}$ The rationale for using this approach is that transmission of infection in our model (as in real life) is driven by combination of the location of agents, pathogen transmissibility per discordant contact and intrinsic characteristics of agents reflecting their susceptibility (or lack of) to infection. Therefore, to represent this multi-faceted transmission in our model, we varied three model parameters by hand (connection range, contact rate, and probability of infection on contact message), until the model outputs approximated empirical data, specifically age-specific incidence rates for chickenpox. ${ }^{27}$ Calibration for this variable was completed once our model generated patterns of disease very similar to what was observed in empirical data. (Fig 2). The best values for probability of infection on contact message, contact rates and connection ranges derived from this calibration process are shown in Table 1. The probability of transmitting infection from a chickenpox breakthrough case and from shingles case were assumed to be 0.3 of the probability of transmitting infection from a normal chickenpox case. ${ }^{32}$ As we only had empirical data for medically-attended chickenpox ${ }^{27}$, we tested different underreporting factors and found that reported chickenpox cases constituted approximately $40 \%$ of all cases in our model (an underreporting factor of 2.5, consistent with previous studies that suggest the degree of underreporting can range between 2.5 and 7.7 in a country where chickenpox is notifiable). ${ }^{37}$. 
301 To further validate our model, we tested model outputs against secondary attack rates for

302

303

304

305

306

307

308

309

310

311

312

313

314

315

316

317

318

319

320

321

322

323

324

325

326

327

328

329

330

331 chickenpox reported in the literature. Our model generated a secondary attack rate of $41 \%$ in comparison to attack rates observed in the household settings, ranging mostly between $60 \%$ and $78 \%$ among unvaccinated contacts (but reported as low as $31 \%$ among individuals $>15$ years old). ${ }^{32,38,39} \mathrm{We}$ considered this a realistic estimate as contacts in our population intuitively should be less intensive than the household contacts represented in the literature. Furthermore, the overall chickenpox incidence and the age-specific proportion of the population with varicella antibody when vaccination was disabled in the model was consistent with Canadian data prior to vaccination (Fig. S3). ${ }^{40,41}$

Second, we ran an automated AnyLogic calibration experiment to determine the values for four other unknown parameters in our model, duration of boosting (DoB), waning of immunity coefficient (WoI) (which was used to calculate the waning of immunity rate), exogenous infection rate (i.e., the number of chickenpox cases brought in from outside the simulated population) and shingles connection range (i.e., modification factor for the connection range for people with shingles, to account for the closer contact required to spread VZV through shingles in comparison to chickenpox). The calibration experiment automatically varied these parameters over continuous ranges in order to minimize the objective function quantifying the difference (square root of the average of square differences) between the model and actual data (i.e., age-specific incidence of shingles as described in Russell et al. ${ }^{4}$ ) (Fig. 2). A full description of the data used in model fitting is shown in Table S1. This automated calibration experiment predicted an exogenous infection rate of 17.8 per year and a shingles connection range modifier of 0.124. These values are shown in Table 1. Furthermore, based on the automated experiment values for DoB of 0.42 years, and a waning of immunity coefficient of 0.45 year, we produced age-specific incidence rates for shingles and chickenpox consistent with empirical data.

Third, using the automated calibration values described above as a starting point, we then further investigated whether different combinations of DoB and WoI could also reproduce empirical data. We compared the incident rates resulting from a range of plausible values for DoB and WoI to the empirical incidence rates for chickenpox and shingles. ${ }^{4,27,42,43}$ At this stage, we considered paired values of DoB and WoI to have satisfied calibration if the resulting overall rate of chickenpox and shingles, over a model run of 100 years on 50,000 population, was within 
$33210 \%$ of the empirical values. ${ }^{42,43}$ Based on these guidelines, we found nine other values for a

333 combination of DoB and WoI that met this step of calibration.

334 Finally, we then ran the ten combinations that met the criteria noted above for a period of

335100 years on a 500,000-population sample (10-fold larger than in the previous step). Output from

336 each run was then compared to empirical data on age-specific incidence rates for chickenpox and

337 shingles. We calculated the absolute median difference between model incidence rates of

338 shingles and empirical data for each age group to determine which combination had the smallest

339 difference as determined by lowest sum of residuals squared. The combination with the lowest

340 sum of residuals squared (27.95) for shingles was then considered our baseline scenario in our

341 main experiment (which represented best fit) (Data Reference 3). The sum of residuals squared

342 from each combination was then compared to the baseline scenario and tested for statistically

343 significant difference using the Mann-Whitney $U$ test at the 5\% level of significance. Based on

344 the findings of the statistical tests and as a form of scenario analysis, we included both the

345 baseline scenario along with any other DoB and WoI combinations that were statistically not

346 different ( $\mathrm{p}$ value $>0.05$ ) as scenarios in our main experiment.

347

348 Main Experiment

349 For each of the six scenarios chosen for the main experiment, we conducted at least 30 paired 350 runs, with and without chickenpox vaccination. Running paired runs for each scenario allowed

351 the measurement of differences in shingles rates with and without vaccination for each DoB and

352 WoI combination. Paired model runs were given the same random seed to ensure consistency

353 between pairs. Chickenpox vaccination was represented as part of a two-dose schedule, as

354 described above. In our model, we implemented chickenpox vaccination started at 25 years after

355 the initialization of the model and continued for 75 years. The count and cumulative incidence

356 rate of shingles cases were compared at the 5\% level of significance using the Mann-Whitney U

357 statistical test between the runs with and without chickenpox vaccination at four different time

358 periods, specifically at 10, 25, 50 and 75 years, following introduction of vaccination.

359

\section{Sensitivity Analysis}

361 We ran several sensitivity analyses that tested how varying vaccination parameters may impact

362 the count of shingles cases following chickenpox vaccination. Specifically, we compared a one- 
363 dose to a two-dose chickenpox vaccine schedule. In a separate set of analyses, we compared

364 coverage rates by moving $10 \%$ of hesitant individuals to vaccine acceptors (higher vaccine

365

366

367

368

369

370

371

372

373

374

375

376

377

378

379

380

381

382

383

384

385

386

387

388

389

390

391

392 coverage) in one sensitivity analysis and $10 \%$ of hesitant individuals to vaccine rejectors (lower vaccine coverage) in the second sensitivity analysis. Furthermore, we tested the impact of removing the boosting of shingles immunity (i.e., positing no added years of protection on contact with a chickenpox/shingles case) to see the overall impact of removing this biological effect from the shingles incidence estimates both before and after chickenpox vaccination.

\section{RESULTS}

\section{Input Calibration}

Based on the last step of our calibration we found that the age-specific shingles residuals for DoB 5 years were not significantly different to five of the other combinations (Table 2). These combinations were then included in our main experiment as six scenarios (Scenario 2-7, sum of residuals squared for shingles ranged from 27.95 to 41.51, p-value $>0.05$ ) (Date Reference 3). All sum of residuals squared for chickenpox by age group were not statistically different for each calibration scenarios (sum of residuals squared for chickenpox ranged from 249.20 to 251.00, pvalue $>0.05$ ). As one of the calibration validity tests, we tried to fit model to empirical data with no boosting, however when we disabled boosting we could not replicate the age-specific incidence rate observed in Alberta prior to vaccination. ${ }^{4}$

\section{Main Experiment}

Chickenpox vaccination led to a large drop in chickenpox cases across all six scenarios. In the baseline scenario, the cumulative incidence of chickenpox had dropped from 1,254 cases per 100,000 person-years pre-chickenpox-vaccination to 193 cases per 100,000 person-years 10 years after the vaccine implementation. The cumulative incidence of chickenpox was further reduced to 49 cases per 100,000 person-years 75 years following vaccination. In comparison, all scenarios from 10-years and 25-years post-vaccination showed significantly greater shingles incidence with vaccination compared to the no- vaccination (Table 3). However, the degree of this increase and its subsequent decline was markedly different between experiments (Fig. 3 and Table 3). For instance, in Scenario 2 there was an increase of approximately 22.47 cases per 100,000 person-years after 10 years; by comparison, in Scenario 7 the magnitude of the increase 
393

394

395

396

397

398

399

400

401

402

403

404

405

406

407

408

409

410

411

412

413

414

415

416

417

\section{Sensitivity Analysis}

419

420

421

422

423

was greater at 99.71 cases per 100,000 person-years over that decade $(p<0.001)$. At 75 years post-vaccination, cumulative incidence ranged from a decline of 69.6 to an increase of 71.3 per 100,000 person-years for 2 and 7 years of boosting respectively $(p<0.001)$. The increase in the incidence of shingles was positively associated with the DoB and showed a positive relationship with cumulative shingles incidence rising with each incremental increase in DoB. By the 75-year interval, the shingles incidence in all experiments was below the rate with no-vaccination (Fig. 3), however the cumulative incidence in Scenarios 5-7 was still higher with vaccination than without. In all our scenarios, vaccination did eventually lower the overall rate of shingles; however, the amount of time was dependent on the DoB and the WoI.

At 10-year interval, all age groups greater than 10 years old showed small but equal increase in the number of shingles cases. However, at each subsequent time point (as a greater number of persons of younger age are protected with chickenpox vaccination from initial infection with the virus), cases of shingles were progressively more concentrated in the older age-groups. In contrast, in the younger age group we observed a decrease in shingles almost immediately following chickenpox vaccination (Fig. 4).

We noted several interesting observations in our model. In the no-vaccination model runs, there was an overall increase in shingles cases even without vaccination; in the baseline scenario, the incidence of shingles was 418 per 100,000 person-years after 10 years and increased to 425 per 100,000 person-year after 75 years. Moreover, the average number of boosts per individual calculated in our model over their life-time (with no chickenpox vaccination) was 1.83 with majority of people receiving 0 or 1 boosts. We found minor differences in chickenpox and shingles incidence between urban and rural communities. The incidence of shingles was slightly higher in rural settings in the absence of vaccination but became lower with vaccination (Fig. S4). Approximately 5\% of urban agents had connections with rural agents (Fig. S10).

None of the vaccination sensitivity analyses had a major impact on the number of shingles cases post vaccination. As expected, we saw an increase in the number of shingles cases with a higher number of vaccine acceptors and therefore higher coverage than baseline. Conversely, we saw fewer shingles cases post chickenpox vaccination when we only gave one dose of the vaccine and when we had more vaccine rejecters, however, the effect was minimal. The difference 
424 between the low coverage (higher number of vaccine rejectors) and the high coverage (lower

425 number of vaccine rejectors) was only 2 shingles cases per 100,000 person-years. By contrast,

426 removing biological effect of boosting had a substantial impact on the number of shingles cases

427 both before and after vaccination, with cases rising to levels much higher than what was seen in

428 Alberta ${ }^{4}$. Without chickenpox vaccination, the shingles rate was very high at 724 cases per

429100,000 person-years. Simultaneously, this is the one analysis where the rates begin to decline

430 immediately following vaccination with a decline in cumulative incidence of 215 per 100,000

431 person-years 75 years after the implementation of the chickenpox vaccine (Table 4).

432

\section{DISCUSSION}

434 Our ABM successfully simulated chickenpox and shingles dynamics over time by creating a

435 500,000-person, distance based-contact network, with detailed representation of boosting and

436 waning of immunity. During the calibration process we re-scaled chickenpox incidence rates to

437 account for the underreporting of chickenpox due to use of the rate of medically-attended

438 chickenpox in published estimates. ${ }^{27} \mathrm{We}$ calibrated the model to six different scenarios for DoB

439 and WoI for shingles, suggesting that many different quantitative values for these two unknown

440 parameters are consistent with the empirical data. Based on this calibration, we determine that

441 shingles incidence-post vaccination is highly sensitive to the values for both DoB and WoI,

442 although all scenarios eventually led to a reduction in shingles incidence rates relative to baseline

443 rates.

444 Infectious disease models can provide valuable insight into the complex relationship

445 between chickenpox and shingles, allowing epidemiologists and biologists to test theories, study

446 the impact of different parameters, and judge the outcomes of various interventions. To date the

447 majority of chickenpox and shingles models, including the only model representing a Canadian

448 population ${ }^{44}$ are aggregate compartmental models, which limit their flexibility and

449 heterogeneity. ${ }^{20,45-49}$ To our knowledge, the only individual-based model was created by

450 Ogunjimi et al. ${ }^{25}$ to combine within- and between host dynamics, and VZV immunological data

451 to estimate boosting characteristics. Our model utilized their representation of the biological

452 conditions for chickenpox and shingles infection and VZV-cell mediated immunity; however, it

453 differs from the Ogunjimi model in several key ways. Ogunjimi’s model represented contacts

454 using a probabilistic method whereas ours implemented a distance-based network and included 
455 an increased contact range for school-aged children. ${ }^{25,50}$ The Ogunjimi model used a population

456 that remained fixed in size and was based on Belgium demographics, while our model

457 implemented an open and non-fixed population based on Alberta data, with realistic

458 demographic changes over time. Furthermore, the Ogunjimi model assumed 100\% vaccine

459 effectiveness and incorporated only a one-dose chickenpox vaccination schedule, while ours

460 included representations of vaccine attitudes as a dynamic predictor of vaccine coverage and

461 probability of primary vaccine failure.

462 Our model concurs with previous models and biological studies that suggest exogenous

463 boosting of VZV immunity is a likely factor in the reactivation of VZV, as we were not able to

464 recreate the empirical data observed in Alberta without incorporating some element of boosting. ${ }^{6}$

465 Longitudinal immunological studies show individuals re-exposed to chickenpox, either on a one-

466 time or continuous basis, have a corresponding increase in VZV-specific immunity. ${ }^{51-53}$

467 However, these studies generally only look at the short-term immunological effects of boosting

468 (up to one year post-exposure) and not everyone is boosted following re-exposure, raising

469 questions about the duration of boosting and the degree, number and quality of exposures needed

470 to produce a boost of VZV-CMI. ${ }^{6}$ A recent study showed that only $17-25 \%$ of grandparents who

471 were exposed to chickenpox received a significant boost in VZV-specific immunity and that this

472 boost typically lasted less than a year. ${ }^{54}$

473 Using our agent-based model, we varied these unknown boosting parameters (e.g., DoB,

474 WoI, degree and probability of boosting on contact) to see how those variations impacted the

475 outcomes of chickenpox vaccination. By varying DoB and WoI simultaneously, we identified

476 several boosting of immunity scenarios that could fit current Alberta data. In comparison, many

477 previous chickenpox and shingles models have made some strict assumptions about boosting of

478 immunity, with the parameter values for the force or duration of boosting set high. For instance,

479 Ouwens et al. ${ }^{20}$ assumed that the force of boosting would be equal to the force of infection, while

480 Brisson et al. ${ }^{21}$ postulated each boost would result in 24 years of protection. It is perhaps not

481 surprising that under these assumptions, many of the compartmental models predicted an

482 increase in shingles following chickenpox vaccination.

483 Our results illustrated that the short-term increase in shingles cases following chickenpox

484 vaccination is largely dependent on the DoB and WoI -- quantities whose values are still widely

485 debated in the literature. Varying these values had a major impact on outcomes of chickenpox 
486 vaccination, with the percentage of increase in incidence rate ranging between $4.8 \%$ and $41.9 \%$

487 (25 years post-vaccination) between the most and least conservative DoB estimates. The only

488 other study to vary the natural DoB, to our knowledge, was by Jan Van Hoek et al. ${ }^{55}$, who found

489 a short natural boosting and a longer shingles vaccine protection leading to variable increase in

490 shingles following chickenpox vaccination. However, in this study, the DoB assumed one of

491 only three values $(7.5,20,42$ years), only varied DoB in conjunction with shingle vaccine

492 boosting, used a compartmental model and did not describe how they calibrated the model to

493 empirical data. ${ }^{55}$ Our experiments with lower durations of boosting predicted increases in

494 shingles cases post-chickenpox vaccination smaller than previous models. ${ }^{21,47,56}$ This is likely

495 because, these DoB were significantly lower than previous models but are consistent with

496 immunological assays used to measure the duration of boosting in grandparents as described in

497 the study above. ${ }^{54}$ Furthermore, the rate of boosting in our model was driven within an age- and

498 distance- based transmission network rather than a random-mixing network, potentially limiting

499 contacts that could produce a boost, which is supported by the fact that our average number of

500 boosts per person was low at 1.83 .

501 Our model results were congruent with other models that demonstrated, over a longer

502 time horizon, shingles cases would decrease significantly following chickenpox vaccination.

503 This decrease is because chickenpox vaccination decreases the burden of illness of chickenpox

504 and the incidence of infection by VZV, thus reducing the population with dormant VZV, and

505 producing a cohort effect as a greater and greater percentage of the population is vaccinated.

506 Empiric studies post-chickenpox vaccination have started to show evidence of this cohort effect,

507 with younger age groups who have received chickenpox vaccination having lower rates of

508 shingles than the corresponding age group prior to vaccination. ${ }^{57,58}$ The ultimate drop in shingles

509 cases will depend largely on what percentage of chickenpox vaccinated cohorts are susceptible to 510 shingles.

511 To date, empirical findings drawn from the era following introduction of chickenpox

512 vaccination are largely inconsistent, making it difficult for policy-makers to know the continued

513 impact of the chickenpox vaccine. While some studies show an increase in rates of shingles

514 following the implementation of chickenpox vaccination, similar studies have shown that this

515 increase started prior to vaccination, and other studies have found rates have stayed the same

516 following vaccination. ${ }^{4,57}$ Different contact and boosting patterns (e.g., number of boosting 
517 events, age at which boosts occur, age of chickenpox infection) in different countries may also

518 shape some of the observed differences in the age-specific incidence rates of shingles by country

519 and potentially the impact of chickenpox vaccination by country. ${ }^{48}$ Two Canadian studies argued

520 that the incidence rate of shingles was increasing prior to chickenpox vaccination

521 implementation and has stayed consistent following the implementation, however, such studies

522 took place only seven and eight years following vaccination, and one study did not adjust for

523 age. ${ }^{4,57}$ Our model demonstrated that at a lower DoB and higher WoI, the perceived impact on

524 shingles rates would be quite small, increasing from 383 cases per 100,000 person-years to 406

525 per 100,000 person-years 10 years after chickenpox vaccination. This small increase may be

526 difficult to measure or observe in empirical data where other factors influence the shingles rates

527 (e.g., shingles vaccination, co-morbid infections, ageing of the population).

528 Our model produced some interesting secondary findings and observations. As with

529 previous models, we found it challenging to account for the rate of shingles infection seen in the

530 youngest age group. ${ }^{25}$ Russell et al. ${ }^{4}$ shows a small but sudden increase in the rate of shingles

531 infection in one- to four-year-olds. We theorized that a substantial proportion of these cases

532 could be due to immunocompromising conditions in young children that may place them at a

533 greater risk of developing shingles. However, it would be interesting to further explore if these

534 individuals alone could account for this increase and if this is a trend that is found across

535 countries. Furthermore, we found that varying chickenpox vaccine coverage (by changing

536 vaccine attitudes within $10 \%$ ) had only a minor impact on shingles incidence. However, greater

537 changes to vaccine coverage levels would eventually realize larger impacts on shingles

538 incidence. Evaluation of disease and vaccination outcomes stratified by urban and rural

539 populations demonstrated that urbanicity did not impact the overall results, suggesting that our

540 model may be robust to uncertainty in population demographics within a given connection

541 frequency between urban and rural population.

542 Although our model is one of the most detailed extant representations of the interaction

543 between chickenpox and shingles, it is subject to limitations. First, we ran our model on a

544 population of 500,000 , raising the question of applicability to larger populations. However, we

545 observed very little deviation in our findings when we ran the model on 50,000 vs. 500,000,

546 suggesting a robustness of results to broad ranges in population size. Second, following a review

547 of the literature, we decided not to include endogenous boosting, as the relevance of endogenous 
548 boosting is debated in the literature and Ogunjimi et al. ${ }^{25}$ found it insignificant. Third, we had

549 difficulty accounting for shingles in younger age groups, and therefore had to adapt out model to 550 fit Canadian data. Fourth, we were only able to vary a couple of the parameters relevant to the 551 boosting of immunity; future research should further explore the impact of changing multiple 552 boosting parameters (e.g., probability of boosting on contact by age). Finally, we used a stylised 553 distance-based network to represent transmission of infection and did not implement a truly age554 dependant contact matrix.

555 Future research and agent-based modelling should focus on studying some of the 556 remaining unknowns surrounding the mechanisms of VZV reactivation, waning and boosting of 557 immunity. ABMs could explore how changing the contact patterns alters the number and type of 558 boosting events, and how this variation may explain the differences in shingles incidence both 559 before and after chickenpox vaccination in different countries. Moreover, there should be 560 ongoing comparison of model results and empirical findings post-chickenpox vaccination, so we 561 can update model parameters to fit with changing data. Our findings highlight the importance of 562 not only studying when and if boosting occurs, but also the level of protection it confers on the 563 individuals. While Ogunjimi et al. ${ }^{54}$ provides a good start to measuring the quantifiable impacts 564 of boosting, studies should measure the longer-term immunological impacts of re-exposure and 565 how those measurements translate to risk of reactivation. Furthermore, future research and 566 models may want to look at the impact of other disease and population factors on the changing

567 epidemiology of shingles, including immunocompromising conditions, co-morbid infections 568 (e.g., CMV), and stress.

\section{CONCLUSION}

571 Our model highlights the importance of not simply knowing when and if the VZV boosting 572 events occur but the specific duration of boosting, as these values can impact the effect of 573 chickenpox vaccination on shingles incidence over time. Our study suggests that over the longer 574 time period, there will be a reduction in shingles incidence driven mostly by the depletion of 575 source of shingles reactivation, suggesting that in the long-term a universal chickenpox vaccine 576 would be a good policy to reduce both chickenpox and shingles cases. However, in the short to 577 medium term some age cohorts may experience an increase in shingles incidence. Our model 578 offers a platform to further explore the relationship between chickenpox and shingles, including 
579 analyzing the impact of different chickenpox vaccination schedules and cost-effectiveness

580 studies.

581

582 ACKNOWLEDGEMENTS

583 Authors acknowledge Sowgat Ibne Mahmud and Nazifa Khan for their contributions to the 584 conception and initial design of the agent-based model. Authors acknowledge contributions of 585 public health department in Alberta for obtaining surveillance data and staff at the University of 586 Saskatchewan Computational Epidemiology and Public Health Informatics Laboratory for use of 587 their equipment to run simulation experiments.

588

589

590

591

592

593

594

595

596

597

598

599

600

601

602

603

604

605 


\section{REFERENCES}

607 1. National Advisory Committee on Immunization. An Advisory Committee Statement:

608 Literature Review on One-Dose and Two-Dose Varicella Vaccination. Canada Commun.

609 Dis. Rep. 36, (2010).

610 2. Cohen, J. I. Herpes Zoster. N. Engl. J. Med. 369, 255-263 (2013).

611 3. Public Health Agency of Canada. Active vaccines: Herpes zoster (shingles) vaccine.

612 (2016). Available at: https://www.canada.ca/en/public-

613 health/services/publications/healthy-living/canadian-immunization-guide-part-4-activevaccines/page-8-herpes-zoster-(shingles)-vaccine.html (Accessed: $10^{\text {th }}$ November 2017).

615

4. Russell, M. L., Dover, D. C., Simmonds, K. A. \& Svenson, L. W. Shingles in Alberta:

616

617

618

619

620

621

622

623

624

625

626

627

628

629

630

631

5. Hales, C., Harpaz, R., Joesoef, M. \& Bialek, S. Examination of links between herpes Before and after publicly funded varicella vaccination. Vaccine 32, 6319-6324 (2014).

zoster incidence and childhood varicella vaccination. Ann. Intern. Med. 159, 739-745 (2013).

6. Ogunjimi, B., Van Damme, P. \& Beutels, P. Herpes Zoster risk reduction through exposure to chickenpox patients: A systematic multidisciplinary review. PLoS One 8, 118 (2013).

7. Levin, M. J. Zoster vaccine. in Vaccine (eds. Plotkin, S. A., Orenstein, W. A. \& Offit, P.) 969-980 (2012).

8. Hope-Simpson, R. E. The nature of herpes zoster: a long-term study and a new hypothesis. Proc. R. Soc. Med. 58, 9-20 (1965).

9. Garnett, G. P. \& Grenfell, B. T. The epidemiology of varicella-zoster virus infections : the influence of varicella on the prevalence of herpes zoster. Epidemiol. Infect. 108, 513-528 (1992).

10. Garnett, G. P. \& Ferguson, N. M. Predicting the effect of varicella vaccine on subsequent

11. World Health Organization. Varicella and herpes zoster vaccines: WHO position paper,

12. European Centre for Disease Prevention and Control. ECDC Guidance: Varicella vaccination in the European Union. (2015).

13. Public Health Agency of Canada. National Advisory Committee on Immunization (NACI): Statement on the recommended use of the herpes zoster vaccine. Canada Commun. Dis. Rep. 36, 1-19 (2010).

14. Ahmed, A., Greensmith, J. \& Aickelin, U. Variance in system dynamics and agent based modelling using the SIR model of infectious disease. in Proceedings of the 26th European Conference on Modelling and Simulation (ECMS) 9-15 (2013). 
644

modeling method for health care delivery research-Part 2: Report of the ISPOR Dynamic Simulation Modeling Emerging Good practices Task Force. Value Heal. 18, 147-160 (2015).

16. Osgood, N. D. Using traditional and agent based toolsets for system dynamics: Present tradeoffs and future evolution. in Proceedings, The 25th International Conference of the System Dynamics Society 19pp (2007).

17. Osgood, N. D. Representing progression and interactions of comorbidities in aggregate and individual-based systems models. in Proceedings, The 27th International Conference of the System Dynamics Society 20pp (2009).

18. Osgood, N. D. Lightening the performance burden of individual-based models through dimensional analysis and scale modeling. Syst. Dyn. Rev. 25, 24pp (2009).

19. Osgood, N. D. Representing heterogeneity in complex feedback system modeling: Computational resource and error scaling. in Proceedings, 22nd International Conference of the System Dynamics Society 46pp (2004).

20. Ouwens, M. J. N. M., Littlewood, K. J., Sauboin, C., Boe, P., Tehard, B., Denis, F., Boelle, P.-Y.\& Alain, S. The impact of 2-dose routine measles, mumps, rubella, and varicella vaccination in France on the epidemiology of varicella and zoster using a dynamic model with an empirical contact matrix. Clin. Ther. 37, 816-829 (2015).

21. Brisson, M., Melkonyan, G., Drolet, M., De Serres, G., Thibeault, R. \& De Wals, P. Modeling the impact of one- and two-dose varicella vaccination on the epidemiology of varicella and zoster. Vaccine 28, 3385-3397 (2010).

22. Guzzetta, G., Poletti, P., Ero, Merler, S. \& Manfredi, P. The Epidemiology of Herpes Zoster After Varicella Immunization Under Different Biological Hypotheses: Perspectives From Mathematical Modeling. Am. J. Epidemiol. 183, 765-773 (2016).

23. Guzzetta, G., Poletti, P., Fava, E. Del, Ajelli, M., Tomba, G. P. S., Merler, S. \& Manfredi, P. Hope-Simpson's progressive immunity hypothesis as a possible explanation for herpes zoster incidence data. Am. J. Epidemiol. 177, 1134-1142 (2013).

24. Government of Alberta. Routine immunization schedule. Alberta (2015). Available at: http://www.health.alberta.ca/health-info/imm-routine-schedule.html. (Accessed: $10^{\text {th }}$ November 2017).

25. Ogunjimi, B., Willem, L., Beutels, P. \& Hens, N. Integrating between-host transmission and within-host immunity to analyze the impact of varicella vaccination on zoster. Elife 4, $1-17$ (2015).

26. Mossong, J., Hens, N., Jit, M., Beutels, P., Auranen, K., Mikolajczyk, R., Massari, M., Salmaso, S., Tomba, G. S., Wallinga, J., Heijne, J., Sadkowska-Todys, M., Rosinka, M. \& Edmunds, W. J. Social contacts and mixing patterns relevant to the spread of infectious diseases. PLoS Med. 5, 0381-0391 (2008)

27 Kwong, J. C., Tanuseputro, P., Zagorski, B., Moineddin, R. \& Chan, K. J. Impact of varicella vaccination on health care outcomes in Ontario, Canada: Effect of a publicly funded program? Vaccine 26, 6006-6012 (2008). 
684

685

686

687

688

689

690

691

692

693

694

695

696

697

698

699

700

701

702

703

704

705

706

707

708

709

710

711

712

713

714

715

716

717

718

719

720

721

722

723

28. Alberta Health. Interactive health data application. (2017). Available at: http://www.ahw.gov.ab.ca/IHDA_Retrieval/selectSubCategoryParameters.do (Accessed: $10^{\text {th }}$ November 2017).

29. Statistics Canada. Pregnancy outcomes by age group (Live births). Government of Canada (2008). Available at: http://www.statcan.gc.ca/tables-tableaux/sumsom/101/cst01/hlth65b-eng.htm. (Accessed: $10^{\text {th }}$ November 2017).

30. Statistics Canada. Life tables, Canada, provinces and territories 2010 to 2012. Government of Canada (2016). Available at: http://www.statcan.gc.ca/pub/84-537-x/84-537x2016006-eng.htm. (Accessed: 10 $0^{\text {th }}$ November 2017).

31. Statistics Canada. Estimates of population, by age group and sex for July 1, Canada, provinces and territories annual (persons unless otherwise noted). Government of Canada (2016). Available at: http://www5.statcan.gc.ca/cansim/a26?id=510001. (Accessed: $10^{\text {th }}$ November 2017).

32. Gershon, A. A., Takahashi, M. T. \& Seward, J. F. Varicella vaccine. in Vaccines (eds. Plotkin, S., Orenstein, W. \& Offit, P.) 837-869 (Elsevier Saunders, 2012).

33. Bonanni, P., Gershon, A., Gershon, M., Kulcsár, A., Papaevangelou, V., Rentier, B., Sadzot-Delvaux, C., Usonis, V., Vesikari, T., Weil-Olivier, C., de Winter, P. \& Wutzler, P. Primary versus secondary failure after varicella vaccination. Pediatr. Infect. Dis. J. 32, e305-e313 (2013).

34. Duncan, J. R., Witkop, C. T., Webber, B. J. \& Costello, A. A. Varicella seroepidemiology in United States air force recruits: A retrospective cohort study comparing immunogenicity of varicella vaccination and natural infection. Vaccine 35, 2351-2357 (2017).

35. Doroshenko, A., Qian, W. \& Osgood, N. D. Evaluation of outbreak response immunization in the control of pertussis using agent-based modeling. PeerJ 4, 1-22 (2016).

36. Grimm, V. Pattern-Oriented Modeling of Agent-Based Complex Systems: Lessons from Ecology. Science, 310, 987-991 (2005).

37. Ciofi Degli Atti, M. L., Rota, M. C., Madolini, D., Bella, A., Gabutti, G., Crovari, P. \& Salmaso, S. Assessment of varicella underreporting in Italy. Epidemiol. Infect. 128, 479484 (2002).

38. Ceyhan, M., Tezer, H. \& Yildirim, I. Secondary attack rate of hepatitis A, varicella and mumps in household settings and reliability of family history to detect seronegative children for necessity of vaccination. Scand.J Infect.Dis. 41, 501-506 (2009).

39. Seward, J. F., Zhang, J. X., Maupin, T. J., Mascola, L. \& Jumaan, A. O. Contagiousness of varicella in vaccinated cases: A household contact study. J. Am. Med. Assoc. 292, 704708 (2004).

40. Public Health Agency of Canada. Varicella (chickenpox). (2012). Available at: http://www.phac-aspc.gc.ca/im/vpd-mev/varicella-eng.php. (Accessed: $10^{\text {th }}$ November 2017). 
724 41. Ratnam, S. Varicella susceptibility in a Canadian population. Can. J. Infect. Dis. 11, 249$725 \quad 53(2000)$.

726

727

728

729

730

731

732

733

734

735

736

737

738

739

740

741

742

743

744

745

746

747

748

749

750

751

752

753

754

755

756

757

758

759

760

761

762

42. Topping, C. J., Høye, T. T. \& Olesen, C. R. Opening the black box-Development, testing and documentation of a mechanistically rich agent-based model. Ecol. Modell. 221, 245255 (2010).

43. Railsback, S. F. \& Grimm, V. Agent-based and individual-based modeling: a practical introduction. (Princeton University Press, 2012).

44. Brisson, M., Edmunds, W. J., Gay, N. J., Law, B. \& De Serres, G. Modelling the impact of immunization on the epidemiology of varicella zoster virus. Epidemiol. Infect. 125, 651-669 (2000).

45. Riche, B., Bricout, H., Kürzinger, M., Roche, S., Etard, J. \& Ecochard, R. Modeling and predicting the long-term effects of various strategies and objectives of varicella- zoster vaccination campaigns. Expert Rev. Vaccines 7, 927-936 (2016).

46. Betta, M., Laurino, M., Pugliese, A., Guzzetta, G., Landi, A. \& Manfredi, P. Perspectives on optimal control of varicella and herpes zoster by mass routine varicella vaccination. Proceeedings R. Soc. B 283, 1-8 (2016).

47. Marziano, V., Poletti, P., Guzzetta, G., Ajelli, M., Manfredi, P., Merler, S. \& Merler, S. The impact of demographic changes on the epidemiology of herpes zoster : Spain as a case study. Proc. R. Soc. B 282, 1-8 (2015).

48. Poletti, P., Melegaro, A., Ajelli, M., Fava, E., Guzzetta, G., Faustini, L., Tomba, G. S., Lopalco, P., Rizzo, C., Merler, S. \& Manfredi, P. Perspectives on the impact of varicella immunization on herpes zoster. A model-based evaluation from three European countries. PLoS One 8, 1-13 (2013).

49. Gao, Z., Gidding, H. F., Wood, J. \& Macintyre, C. R. Modelling the impact of one-dose vs .two-dose vaccination regimens on the epidemiology of varicella zoster virus in Australia. Epidemiol. Infect. 138, 457-468 (2010).

50. Ogunjimi, B., Hens, N., Goeyvaerts, N., Aerts, M., Van Damme, P. \& Beutels, P. Using empirical social contact data to model person to person infectious disease transmission: An illustration for varicella. Math. Biosci. 218, 80-87 (2009).

51. Arvin, A. M., Koropchak, C. M. \& Wittek, A. E. Immunologic evidence of reinfection with varicella-zoster virus. J. Infect. Dis. 148, 200-205 (2017).

52. Vossen, M. T. M., Gent, M., Weel, J. F. L., de Jong, M. D., van Lier, R. A. W. \& Kuijpers, T. W. Development of Virus-Specific CD4 + T Cells on Reexposure to Varicella-Zoster Virus. J. Infect. Dis. 190, 72-82 (2004).

53. Ogunjimi, B., Smits, E., Heynderickx, S., Van den Bergh, J., Bilcke, J., Jansens, H., Malfait, R., Ramet, J., Maecker, H. T., Cools, N., Beutels, P. \& Van Damme, P. Influence of frequent infectious exposures on general and varicella-zoster virus-specific immune responses in pediatricians. Clin. Vaccine Immunol. 21, 417-426 (2014).

54. Ogunjimi, B., Van den Bergh, J., Meysman, P., Heynderickx, S., Bergs, K., Jansen, H., 
763

Leuridan, E., Vorsters, A., Goossens, H., Laukens, K., Cools, N., Van Tendeloo, V., Hens, N., Van Damme, P., Smits, E. \& Beutels, P. Multidisciplinary study of the secondary immune response in grandparents re-exposed to chickenpox. Sci. Rep. 7, 1-11 (2017).

55. Jan van Hoek, A., Melegaro, A., Zagheni, E., Edmunds, W. J. \& Gay, N. Modelling the impact of a combined varicella and zoster vaccination programme on the epidemiology of varicella zoster virus in England. Vaccine 29, 2411-2420 (2011).

56. Brisson, M., Edmunds, W. J., Law, B., Gay, N. J., Walld, R., Brownell, M., Roos, L. \& De Serres, G. Epidemiology of varicella zoster virus infection in Canada and the United Kingdom. Epidemiol. Infect. 127, 305-314 (2001).

57. Marra, F., Chong, M. \& Najafzadeh, M. Increasing incidence associated with herpes zoster infection in British Columbia, Canada. BMC Infect. Dis. 16, 589-602 (2016).

58. Humes, E. A., Weinberger, D. M., Kudish, K. S. \& Hadle, J. L. Trends in hospitalizations with primary varicella and herpes zoster during the prevaricella and initial postvaricella and herpes zoster vaccine eras, Connecticut, 1994-2012. Ofid 2, 1-8 (2015).

\section{DATA REFERENCES}

1. McDonald, W., Rafferty, E., Qian, W., Osgood, N.D., Doroshenko, A. Chickenpox and shingles ABM. https://figshare.com/s/0979829d7775db17d400

2. Rafferty, E., McDonald, W., E., Qian, W., Osgood, N.D., Doroshenko, A. Chickenpox and shingles ABM_connection and contact frequency profile. https://figshare.com/s/8ece46bffb29f019c4be

3. Rafferty, E., McDonald, W., E., Qian, W., Osgood, N.D., Doroshenko, A. Sums of residuals squared used to determine scenario selection in model calibration and experimentation. https://figshare.com/s/9d90becfc2581b12f35c

\section{FIGURE LEGENDS}

Fig. 1. Statechart structure. (A) Disease and protection. (B) Chickenpox vaccination schedule. (C) Shingles vaccination schedule. (D) Demographics.

Fig. 2. Model-generated (blue line) and published (red line) age-specific incidence rates for chickenpox and shingles at time 0: model calibration - baseline scenario. (A) Model data is based on multiple simulations for the baseline scenario; empirical data as described by Kwong et 
$799 a l .{ }^{27}$; best fit is achieved at 2.5 multiple of empirical data. (B) Model data is based on multiple 800 simulations for the baseline scenario; empirical data as described by Russell et al. ${ }^{4}$ In all images 801 the blue polygon represents pointwise minimum and maximum values.

802

803 Fig. 3. All-ages shingles annual incidence over time after implementing chickenpox 804 vaccination by duration of boosting, multiple simulations. (A) Scenario 2 ( $\mathrm{DoB}=2)$. (B)

805 Scenario $3(\mathrm{DoB}=3)$. (C) Scenario $4(\mathrm{DoB}=4)$. (D) Scenario $5(\mathrm{DoB}=5)$. (E) Scenario 6

806 (DoB=6). (F) Scenario $7(\mathrm{DoB}=7)$. In all images the blue polygon represents pointwise minimum 807 and maximum values.

808

809

Fig. 4. Mean cumulative count of shingles cases added/averted by the age group and time

810 point, baseline scenario. Positive number on the y-axis indicates the number of shingles cases

811 added and negative number - the number of shingles cases averted. 
Figure 1

Statechart structure.

(A) Disease and protection. (B) Chickenpox vaccination schedule. (C) Shingles vaccination schedule. (D) Demographics.

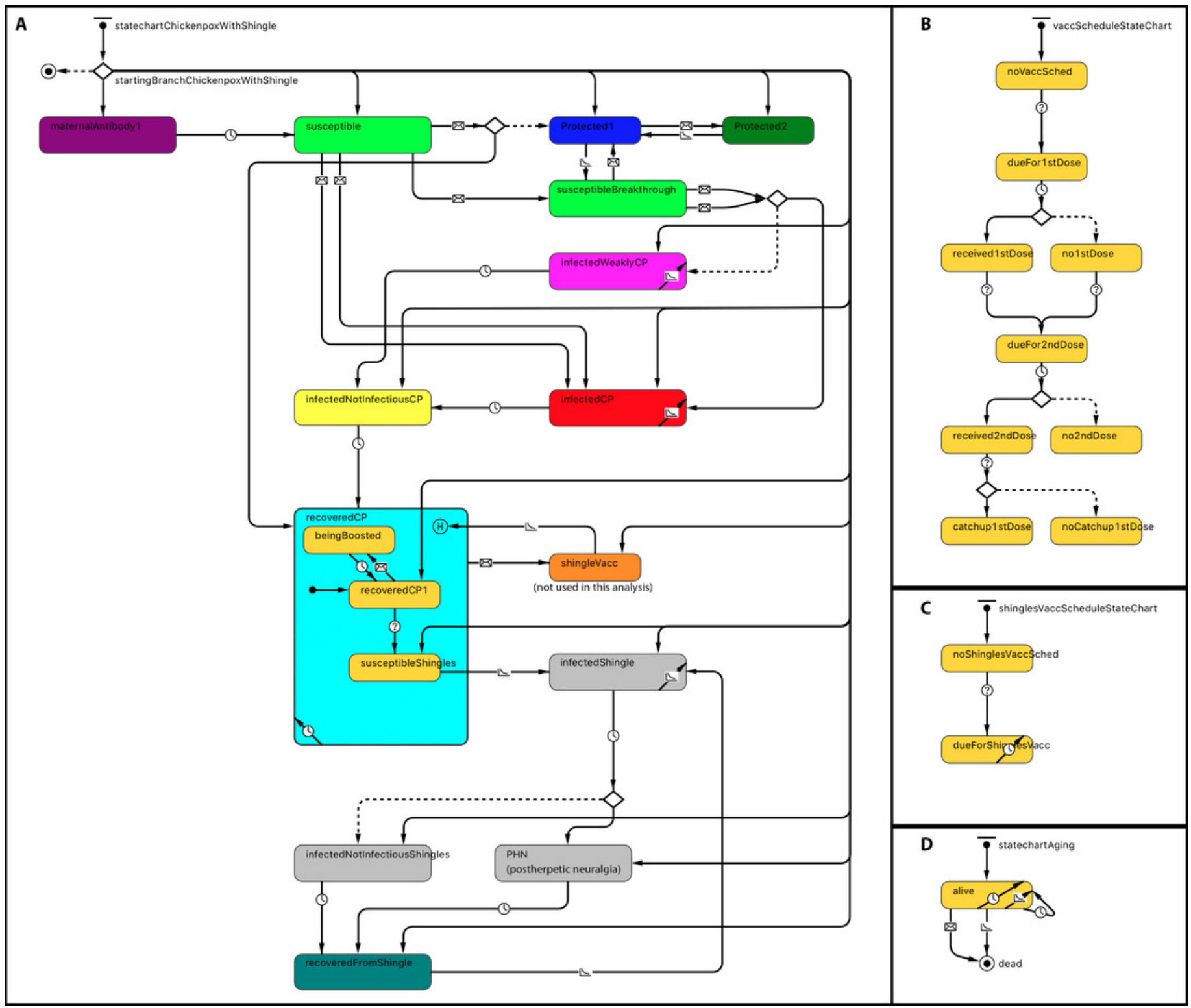




\section{Figure 2 (on next page)}

Model-generated (blue line) and published (red line) age-specific incidence rates for chickenpox and shingles at time 0 : model calibration - baseline scenario.

(A) Model data is based on multiple simulations for the baseline scenario; empirical data as described by Kwong et al. ${ }^{27}$; best fit is achieved at 2.5 multiple of empirical data. (B) Model data is based on multiple simulations for the baseline scenario; empirical data as described by Russell et al. ${ }^{4}$ In all images the blue polygon represents pointwise minimum and maximum values. 
PeerJ

(A) Manuscript to be reviewed

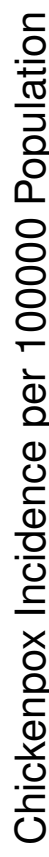

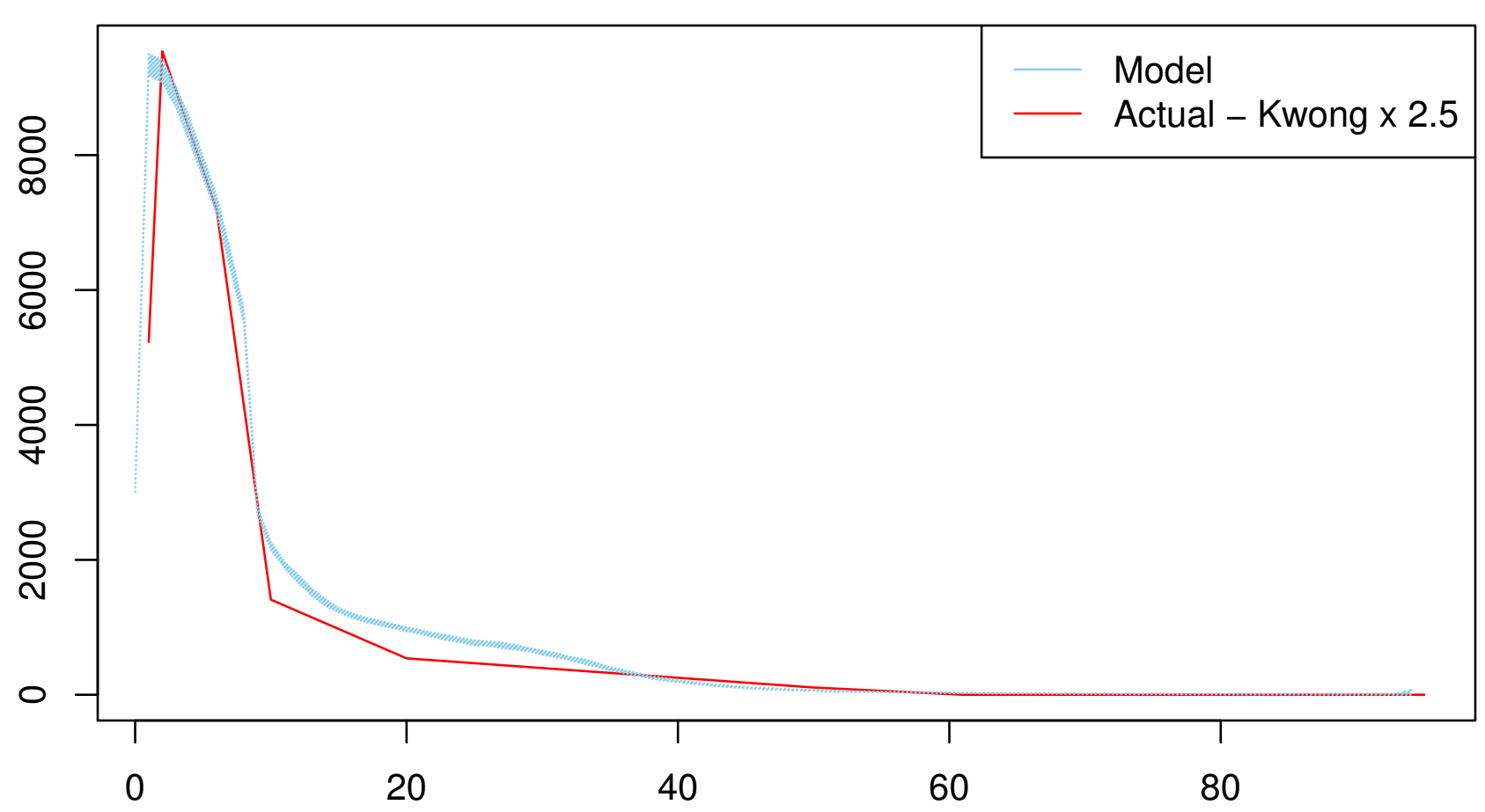

Age

(B)

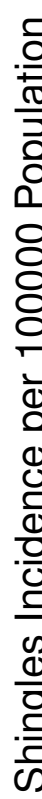

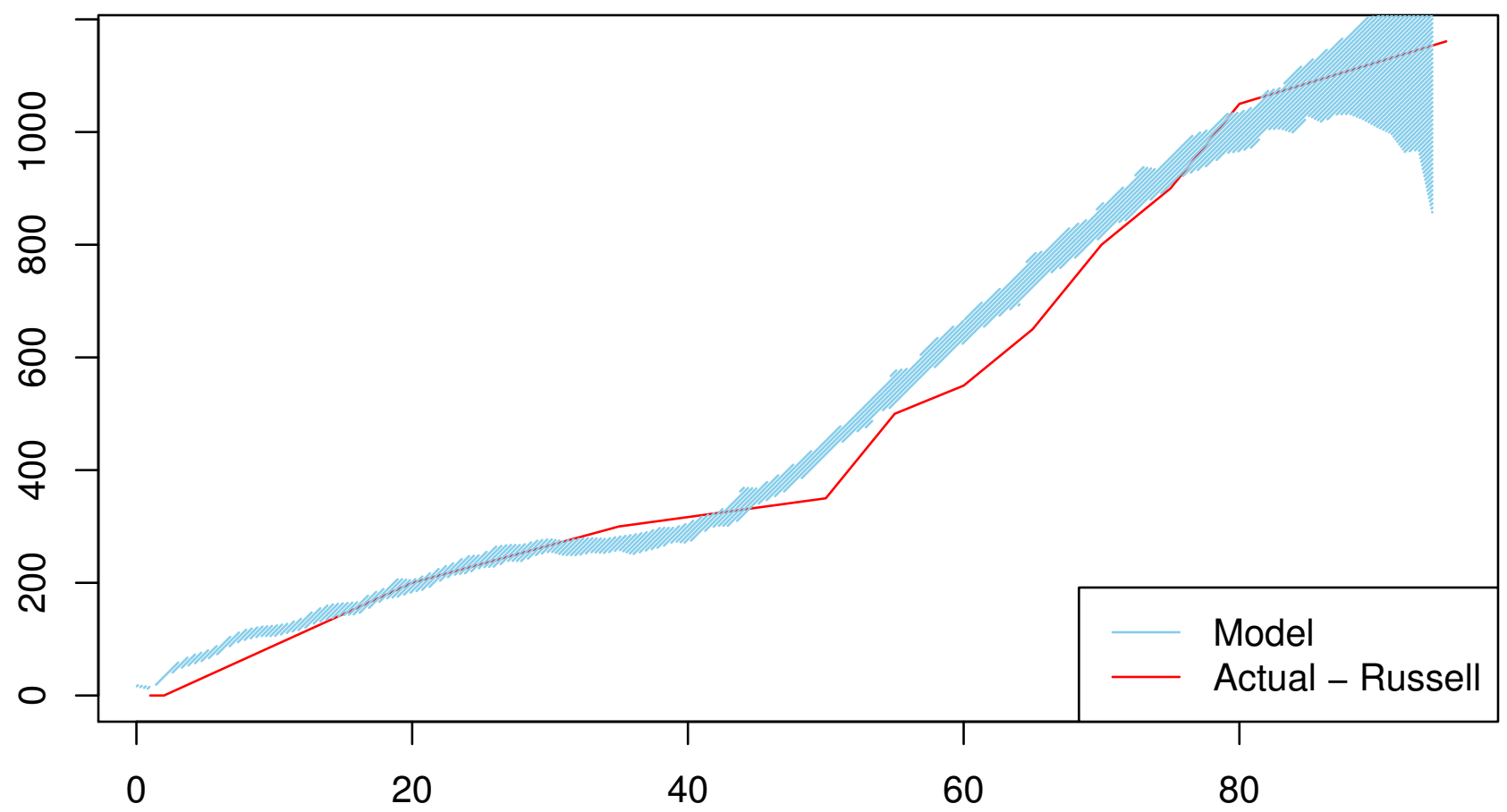

PeerJ reviewing PDF | (2017:08:19793:4:0:NEW 4 May 2018) 
Figure 3 (on next page)

All-ages shingles annual incidence over time after implementing chickenpox vaccination by duration of boosting, multiple simulations.

(A) Scenario $2(D \circ B=2)$. (B) Scenario $3(D \circ B=3)$. (C) Scenario 4 ( $D \circ B=4)$. (D) Scenario 5 $(D o B=5)$. (E) Scenario $6(D \circ B=6)$. $(F)$ Scenario $7(D o B=7)$. In all images the blue polygon represents pointwise minimum and maximum values. 


\section{Figure 4 (on next page)}

Mean cumulative count of shingles cases added/averted by the age group and time point, baseline scenario.

Positive number on the $y$-axis indicates the number of shingles cases added and negative number - the number of shingles cases averted. 


\section{Table 1 (on next page)}

Data sources, key parameter values and values for calibration. 
1 Table 1. Data sources, key parameter values and values for calibration.

\begin{tabular}{|c|c|c|c|c|}
\hline $\begin{array}{l}\text { Parameter } \\
\text { category }\end{array}$ & Parameter Name & Description & Value & $\begin{array}{l}\text { Reference or } \\
\text { calibration }\end{array}$ \\
\hline \multirow[t]{2}{*}{ Demographics } & $\begin{array}{l}\text { Population size } \\
\text { (Persons) }\end{array}$ & $\begin{array}{l}\text { Population size at the model's } \\
\text { initialization. }\end{array}$ & 500,000 & \\
\hline & $\begin{array}{l}\text { Mortality and fertility } \\
\text { rates }\end{array}$ & $\begin{array}{l}\text { Life tables for Alberta and pregnancy } \\
\text { outcomes (live birth) for Canada by age } \\
\text { group were used to estimate mortality rates } \\
\text { and fertility rates in our population }\end{array}$ & Data available online & $\begin{array}{l}\text { Statistics Canada } \\
29-31\end{array}$ \\
\hline \multirow[t]{5}{*}{$\begin{array}{l}\text { Disease } \\
\text { Mechanisms }\end{array}$} & $\begin{array}{l}\text { Initial cell-mediated } \\
\text { immunity VZV }\end{array}$ & $\begin{array}{l}\text { The distribution across the population of } \\
\text { cell-mediated immunity for shingles } \\
\text { derived from initial infection with varicella } \\
\text { zoster virus. (Fig. S1) }\end{array}$ & $\begin{array}{l}\text { Max }(0.001, \text { normal } \\
(0.05,1))\end{array}$ & Ogunjimi et al. ${ }^{25}$ \\
\hline & Force of reactivation & $\begin{array}{l}\text { Represents the distribution of force of } \\
\text { reactivation for shingles. It is a unitless } \\
\text { value that is compared to the initial cell- } \\
\text { mediate immunity to calculate the 'waning } \\
\text { of immunity time'. (Fig. S1) }\end{array}$ & $\begin{array}{l}\text { Gamma distribution } \\
(2,0.1,0)\end{array}$ & Ogunjimi et al. ${ }^{25}$ \\
\hline & $\begin{array}{l}\text { Waning of immunity } \\
\text { coefficient shingles } \\
\text { (WoI) }\end{array}$ & $\begin{array}{l}\text { Coefficient to determine the annual loss of } \\
\text { protection based on VZV-CMI. }\end{array}$ & $\begin{array}{l}\text { Values tested in } \\
\text { calibration: } 0.45-0.93 \\
\text { Values included in the } \\
\text { analysis: } 0.50-0.74\end{array}$ & Calibration- $3^{\S}$ \\
\hline & $\begin{array}{l}\text { Waning of immunity } \\
\text { rate shingles }\end{array}$ & $\begin{array}{l}\text { Annual loss of protection based on VZV- } \\
\text { CMI. }\end{array}$ & 0.4 & Ogunjimi et al. ${ }^{25}$ \\
\hline & Duration of & Number of years before your protection & Values tested in & Calibration- $3^{\S}$ \\
\hline
\end{tabular}




\begin{tabular}{|c|c|c|c|c|}
\hline & $\begin{array}{l}\text { exogenous boosting } \\
\text { (DoB) }\end{array}$ & $\begin{array}{l}\text { returns to previous levels following a } \\
\text { boost. }\end{array}$ & $\begin{array}{l}\text { calibration: } 0.42-10 \\
\text { Values included in the } \\
\text { analysis: } 2-7\end{array}$ & \\
\hline \multirow[t]{2}{*}{$\begin{array}{l}\text { Disease } \\
\text { Propagation }\end{array}$} & $\begin{array}{l}\text { Exogenous infection } \\
\text { rate }(1 / \text { Year })\end{array}$ & $\begin{array}{l}\text { Represents rate per year of chickenpox } \\
\text { infection imported from outside the model } \\
\text { population. }\end{array}$ & 17.83 & Calibration-2* \\
\hline & $\begin{array}{l}\text { Probability of } \\
\text { infection on contact } \\
\text { message }\end{array}$ & $\begin{array}{l}\text { Represents the probability of infection per } \\
\text { contact message received by a susceptible } \\
\text { agent in a model. }\end{array}$ & $\begin{array}{l}\text { Normal: } 0.78 \\
\text { Breakthrough: } 0.234 \\
\text { Shingles: } 0.234\end{array}$ & $\begin{array}{l}\text { Calibration-1 } \\
\text { Gershon et al. }\end{array}$ \\
\hline \multirow[t]{5}{*}{$\begin{array}{l}\text { Network } \\
\text { characteristics }\end{array}$} & $\begin{array}{l}\text { Connection Range } \\
\text { (Length) }\end{array}$ & $\begin{array}{l}\text { Distance of an individual's connection } \\
\text { range. The range depended on whether you } \\
\text { were included in the preferential mixing } \\
\text { age or the normal mixing age. }\end{array}$ & $\begin{array}{l}\text { Preferential Range }= \\
21.245 \\
\text { Normal Range }=8.958\end{array}$ & $\begin{array}{l}\text { Calibration-1 } \\
\text { Mossong et al. }{ }^{26}\end{array}$ \\
\hline & $\begin{array}{l}\text { Base contact rate } \\
\text { (1/Day) }\end{array}$ & $\begin{array}{l}\text { Number of contacts per agent per day, } \\
\text { which dependent on if you were part of the } \\
\text { preferential or normal age range. }\end{array}$ & $\begin{array}{l}\text { Preferential contact } \\
\text { rate }=20 ; \text { Normal } \\
\text { contact rate }=30.124\end{array}$ & Calibration-1 \\
\hline & & & & Mossong et al. ${ }^{26}$ \\
\hline & $\begin{array}{l}\text { Shingles connection } \\
\text { range modifier }\end{array}$ & $\begin{array}{l}\text { A ratio to lower the connection range of } \\
\text { individuals with } \mathrm{HZ} \text { to make it less } \\
\text { infectious than } \mathrm{CP} \text {. }\end{array}$ & 0.124 & Calibration-2* \\
\hline & $\begin{array}{l}\text { Preferential mixing } \\
\text { age (Year) }\end{array}$ & $\begin{array}{l}\text { Age group where we have increase the } \\
\text { connection range and base contact rate to } \\
\text { better reflect the dynamics in the } \\
\text { population. }\end{array}$ & $1-9$ years & Kwong et al. ${ }^{27}$ \\
\hline
\end{tabular}




\begin{tabular}{|c|c|c|c|c|}
\hline & $\begin{array}{l}\text { Population density } \\
\text { (Agents per length) }\end{array}$ & $\begin{array}{l}\text { Represents the number of agents per } \\
\text { arbitrary distance for urban and rural } \\
\text { population. This parameter in combination } \\
\text { with connection range determines the } \\
\text { number of connections an agent has in our } \\
\text { model. }\end{array}$ & $\begin{array}{l}\text { Urban: } 0.3 \\
\text { Rural: } 0.2\end{array}$ & \\
\hline \multirow{7}{*}{$\begin{array}{l}\text { Chickenpox } \\
\text { vaccine } \\
\text { parameters }\end{array}$} & $\begin{array}{l}\text { Vaccination attitude } \\
\text { in the population }(\%)\end{array}$ & $\begin{array}{l}\text { Distribution of vaccine rejecter, hesitant } \\
\text { and acceptors in the population. }\end{array}$ & $\begin{array}{l}\text { Acceptor }=65, \text { Hesitant } \\
=30, \text { Rejecter }=5\end{array}$ & \multirow{4}{*}{$\begin{array}{l}\text { Vaccine coverage } \\
\text { generated by the } \\
\text { model was } \\
\text { referenced by } \\
\text { vaccine coverage } \\
\text { reported by } \\
\text { Alberta Health }{ }^{28}\end{array}$} \\
\hline & $\begin{array}{l}\text { Probability Catch-Up } \\
(\%)\end{array}$ & $\begin{array}{l}\text { Probability that an individual will get a } \\
\text { catch-up vaccine when due for second } \\
\text { dose vaccination. }\end{array}$ & 55 & \\
\hline & $\begin{array}{l}\text { Probability first dose } \\
\text { vaccination }(\%)\end{array}$ & $\begin{array}{l}\text { Probability an individual will get first dose } \\
\text { vaccination given their vaccine attitude. }\end{array}$ & $\begin{array}{l}\text { Acceptor }=97 \\
\text { Hesitator }=75, \\
\text { Rejecter }=3\end{array}$ & \\
\hline & $\begin{array}{l}\text { Probability second } \\
\text { dose vaccination }(\%)\end{array}$ & $\begin{array}{l}\text { Probability an individual will get second } \\
\text { dose vaccination given they received first } \\
\text { dose vaccine. }\end{array}$ & $\begin{array}{l}\text { Acceptor }=98, \\
\text { Hesitator }=82, \\
\text { Rejecter }=33\end{array}$ & \\
\hline & \multirow[t]{2}{*}{$\begin{array}{l}\text { Primary vaccine } \\
\text { failure chickenpox } \\
(\%)\end{array}$} & \multirow[t]{2}{*}{$\begin{array}{l}\text { The percent of individual that do not have } \\
\text { an immune response to CP vaccination. }\end{array}$} & \multirow[t]{2}{*}{$\begin{array}{l}1^{\text {st }} \text { dose }=16-24 \\
2^{\text {nd }} \text { dose }=5-16\end{array}$} & $\begin{array}{l}\text { Gershon et al. }{ }^{32} \\
\text { Bonanni et al. }{ }^{33}\end{array}$ \\
\hline & & & & Duncan et al. ${ }^{34}$ \\
\hline & $\begin{array}{l}\text { Waning of } \\
\text { chickenpox vaccine } \\
\text { immunity (1/Year) }\end{array}$ & $\begin{array}{l}\text { The rate that chickenpox vaccine } \\
\text { immunity wanes each year. }\end{array}$ & $\begin{array}{l}1^{\text {st }} \text { dose protected }=0.02 \\
2^{\text {nd }} \text { dose protected }=0.00\end{array}$ & Gershon et al. ${ }^{32}$ \\
\hline
\end{tabular}
input parameters by hand until the model outputs approximated age-specific incidence of chickenpox, adjusted for under-reporting. 
4 *Calibration-2: Automated (algorithmic) AnyLogic calibration experiment to determine the values of exogenous infection rate and 5 shingles connection range modifier.

6 Calibration-3: Testing a range of plausible values for DoB and WoI by statistically fitting to the empirical incidence rates for 7 chickenpox and shingles 
Table 2 (on next page)

Calibration results. 
1 Table 2. Calibration Results

\begin{tabular}{|c|c|c|c|}
\hline & $\begin{array}{l}\text { Duration of Boosting- } \\
\text { DoB (years) }\end{array}$ & $\begin{array}{l}\text { Waning of Immunity } \\
\text { Coefficient- WoI } \\
\text { (1/year) }\end{array}$ & P-values ${ }^{1}$ \\
\hline Combination $^{2}$ & 0.42 & 0.45 & $<0.001$ \\
\hline Combination 2 & 2 & 0.50 & 0.051 \\
\hline Combination 3 & 3 & 0.55 & 0.313 \\
\hline Combination 4 & 4 & 0.60 & 0.052 \\
\hline $\begin{array}{l}\text { Combination } 5 \\
\text { (Baseline Scenario) }\end{array}$ & 5 & 0.63 & Reference \\
\hline Combination 6 & 6 & 0.68 & 0.963 \\
\hline Combination 7 & 7 & 0.74 & 0.121 \\
\hline Combination 8 & 8 & 0.79 & 0.001 \\
\hline Combination 9 & 9 & 0.85 & $<0.001$ \\
\hline Combination 10 & 10 & 0.93 & $<0.001$ \\
\hline
\end{tabular}

$2 \quad{ }^{1} \mathrm{P}$-values for Mann-Whitney U test comparing age-specific shingles incidence sum of residuals squared for DoB 5

3 years to all other scenarios. Calibrations scenarios deemed statistically not different (i.e., p-value $>0.05$ ) were

4 included in the main experiment. Calibration scenarios which were statistically different from the best-fit calibration 5 experiment were excluded.

$6{ }^{2}$ Represents combinations of DoB and WoI, all other parameters in the model stayed the same. 


\section{Table 3(on next page)}

Change in all-ages cumulative incidence of shingles over 75 years after implementation of chickenpox vaccination, by scenario and time period. 
1 Table 3. Change in all-ages cumulative incidence of shingles over 75 years after

2 implementation of chickenpox vaccination, by scenario and time period.

\begin{tabular}{|c|c|c|c|c|c|c|c|c|}
\hline \multirow{3}{*}{\begin{tabular}{|l} 
\\
$\begin{array}{l}\text { Scenario } \\
\text { number }\end{array}$
\end{tabular}} & \multicolumn{8}{|c|}{ Time periods } \\
\hline & \multicolumn{2}{|l|}{ T0-T10 } & \multicolumn{2}{|l|}{ T0-T25 } & \multicolumn{2}{|l|}{ T0-T50 } & \multicolumn{2}{|l|}{ T0-T75 } \\
\hline & \begin{tabular}{|l} 
Cumulative \\
incidence- \\
chickenpox \\
vaccination \\
scenario $^{1}$ \\
\end{tabular} & $\begin{array}{l}\text { Change in } \\
\text { cumulative } \\
\text { incidence }^{2,3} \\
(95 \% \text { CI })\end{array}$ & \begin{tabular}{|l|} 
Cumulative \\
incidence- \\
chickenpox \\
vaccination \\
scenario \\
\end{tabular} & $\begin{array}{l}\text { Change in } \\
\text { cumulative } \\
\text { incidence } \\
(95 \% \text { CI })\end{array}$ & \begin{tabular}{|l} 
Cumulative \\
incidence- \\
chickenpox \\
vaccination \\
scenario \\
\end{tabular} & $\begin{array}{l}\text { Change in } \\
\text { cumulative } \\
\text { incidence } \\
(95 \% \text { CI })\end{array}$ & \begin{tabular}{|l|} 
Cumulative \\
incidence- \\
chickenpox \\
vaccination \\
scenario \\
\end{tabular} & $\begin{array}{l}\text { Change in } \\
\text { cumulative } \\
\text { incidence } \\
(95 \% \mathrm{CI})\end{array}$ \\
\hline Scenario 2 & 405.68 & $\begin{array}{l}22.47 \\
(21.91 \\
22.99)\end{array}$ & 402.88 & $\begin{array}{l}18.36 \\
(17.94, \\
18.78) \\
\end{array}$ & 375.12 & $\begin{array}{l}-8.64 \\
(-9.06 \\
-8.21) \\
\end{array}$ & 313.53 & $\begin{array}{l}-69.60 \\
(-70.11 \\
-69.09)\end{array}$ \\
\hline Scenario 3 & 452.80 & $\begin{array}{l}41.13 \\
(40.24, \\
42.02)\end{array}$ & 461.01 & $\begin{array}{l}48.18 \\
(47.72, \\
48.65) \\
\end{array}$ & 437.09 & $\begin{array}{l}23.92 \\
(23.46, \\
24.37) \\
\end{array}$ & 365.03 & $\begin{array}{l}-48.38 \\
(-48.96 \\
-47.81) \\
\end{array}$ \\
\hline Scenario 4 & 492.59 & $\begin{array}{l}59.93 \\
(59.02 \\
60.83) \\
\end{array}$ & 515.86 & $\begin{array}{l}82.16 \\
(81.62, \\
82.69) \\
\end{array}$ & 496.86 & $\begin{array}{l}61.43 \\
(60.88, \\
62.00)\end{array}$ & 414.04 & $\begin{array}{l}-22.45 \\
(-23.22, \\
-21.67)\end{array}$ \\
\hline $\begin{array}{l}\text { Baseline } \\
\text { Scenario }\end{array}$ & 490.00 & $\begin{array}{l}71.32 \\
(70.19 \\
72.45)\end{array}$ & 530.17 & $\begin{array}{l}109.23 \\
(108.48 \\
109.98) \\
\end{array}$ & 520.47 & $\begin{array}{l}97.38 \\
(96.69, \\
98.09) \\
\end{array}$ & 434.75 & $\begin{array}{l}9.57 \\
(8.66, \\
10.47) \\
\end{array}$ \\
\hline Scenario 6 & 513.03 & $\begin{array}{l}85.33 \\
(83.22, \\
87.43) \\
\end{array}$ & 574.61 & $\begin{array}{l}145.00 \\
(143.50 \\
146.50) \\
\end{array}$ & 572.32 & $\begin{array}{l}139.06 \\
(137.80 \\
140.31) \\
\end{array}$ & 476.03 & $\begin{array}{l}40.04 \\
(38.89 \\
41.20)\end{array}$ \\
\hline Scenario 7 & 538.11 & $\begin{array}{l}99.71 \\
(97.98, \\
101.44) \\
\end{array}$ & 627.29 & \begin{tabular}{|l}
185.73 \\
$(184.10$, \\
$186.51)$ \\
\end{tabular} & 632.65 & $\begin{array}{l}185.73 \\
(184.85, \\
186.61) \\
\end{array}$ & 522.70 & $\begin{array}{l}71.33 \\
(70.46, \\
72.21) \\
\end{array}$ \\
\hline
\end{tabular}

$3{ }^{1}$ Average shingles cumulative incidence with chickenpox vaccination per 100,000 person-years (averaged over 30 or

4 more model runs).

$5 \quad{ }^{2}$ Change in shingles cumulative incidence per 100,000 person-years calculated as the average shingles incidence

6 with chickenpox vaccination minus the average shingles incidence without chickenpox vaccination. Positive number

7 represents an increase in cumulative incidence and negative number - a decrease.

$8{ }^{3}$ Using Mann-Whitney $U$ test all changes in cumulative incidence for every time and scenario combination were

9 statistically significant $(\mathrm{p}<0.05)$. 


\section{Table 4 (on next page)}

Sensitivity analysis - change in all-ages cumulative incidence of shingles over 75 years after implementation of chickenpox vaccination, by scenario and time period.

${ }^{1}$ Average shingles cumulative incidence with chickenpox vaccination per 100,000 personyears ( averaged over 30 or more model runs ). ${ }^{2}$ Change in shingles cumulative incidence per 100,000 person-years calculated as the average shingles incidence with chickenpox vaccination minus the average shingles incidence without chickenpox vaccination. Positive number represents an increase in cumulative incidence and negative number - a decrease. ${ }^{3}$ Sensitivity Analysis 1 - One-dose vaccination schedule; Sensitivity Analysis 2 - Lower coverage rates; Sensitivity Analysis 3 - Higher coverage rates; Sensitivity Analysis 4 Removing biological effect of boosting. ${ }^{4} U$ sing Mann-Whitney $U$ test all changes in cumulative incidence for every time and scenario combination were statistically significant $(p<0.05)$. 
1 Table 4. Sensitivity Analysis - change in all-ages cumulative incidence of shingles over 75 years 2 after implementation of chickenpox vaccination, by scenario and time period.

\begin{tabular}{|c|c|c|c|c|c|c|c|c|}
\hline & & & & Tin & periods & & & \\
\hline & T0-T10 & & T0-T25 & & T0-T50 & & T0-T75 & \\
\hline $\begin{array}{l}\text { Sensitivity } \\
\text { analysis } \\
\text { number }^{3}\end{array}$ & $\begin{array}{l}\text { Cumulative } \\
\text { incidence- } \\
\text { chickenpox } \\
\text { vaccination } \\
\text { scenario }^{1} \\
\end{array}$ & $\begin{array}{l}\text { Change in } \\
\text { cumulative } \\
\text { incidence }^{2,4} \\
(95 \% \text { CI })\end{array}$ & $\begin{array}{l}\text { Cumulative } \\
\text { incidence- } \\
\text { chickenpox } \\
\text { vaccination } \\
\text { scenario }^{1} \\
\end{array}$ & $\begin{array}{l}\text { Change in } \\
\text { cumulative } \\
\text { incidence } \\
(95 \% \text { CI })\end{array}$ & $\begin{array}{l}\text { Cumulative } \\
\text { incidence- } \\
\text { chickenpox } \\
\text { vaccination } \\
\text { scenario } \\
\end{array}$ & $\begin{array}{l}\text { Change in } \\
\text { cumulative } \\
\text { incidence } \\
(95 \% \text { CI })\end{array}$ & \begin{tabular}{|l} 
Cumulative \\
incidence- \\
chickenpox \\
vaccination \\
scenario \\
\end{tabular} & $\begin{array}{l}\text { Change in } \\
\text { cumulative } \\
\text { incidence } \\
(95 \% \text { CI })\end{array}$ \\
\hline $\begin{array}{l}\text { Baseline } \\
\text { scenario }\end{array}$ & 490.00 & $\begin{array}{l}71.32 \\
(70.19 \\
72.45) \\
\end{array}$ & 530.17 & $\begin{array}{l}109.23 \\
(108.48, \\
109.98) \\
\end{array}$ & 520.47 & $\begin{array}{l}97.38 \\
(96.69, \\
98.09) \\
\end{array}$ & 434.75 & $\begin{array}{l}9.57 \\
(8.66, \\
10.47) \\
\end{array}$ \\
\hline $\begin{array}{l}\text { Sensitivity } \\
\text { Analysis } 1\end{array}$ & 489.17 & $\begin{array}{l}70.49 \\
(69.30, \\
71.67) \\
\end{array}$ & 527.77 & $\begin{array}{l}106.83 \\
(106.08, \\
107.58) \\
\end{array}$ & 514.28 & $\begin{array}{l}91.20 \\
(90.50, \\
91.89) \\
\end{array}$ & 435.04 & $\begin{array}{l}9.86 \\
(9.01 \\
10.71) \\
\end{array}$ \\
\hline $\begin{array}{l}\text { Sensitivity } \\
\text { Analysis } 2\end{array}$ & 488.77 & $\begin{array}{l}70.09 \\
(68.88, \\
71.31) \\
\end{array}$ & 529.12 & $\begin{array}{l}108.18 \\
(107.39, \\
108.97) \\
\end{array}$ & 519.36 & $\begin{array}{l}96.28 \\
(95.64, \\
96.91) \\
\end{array}$ & 434.68 & $\begin{array}{l}8.02 \\
(8.70 \\
10.30) \\
\end{array}$ \\
\hline $\begin{array}{l}\text { Sensitivity } \\
\text { Analysis } 3\end{array}$ & 490.54 & $\begin{array}{l}71.86 \\
(70.48, \\
73.24) \\
\end{array}$ & 530.73 & $\begin{array}{l}109.79 \\
(109.02 \\
110.57) \\
\end{array}$ & 520.84 & $\begin{array}{l}97.75 \\
(97.05 \\
98.46) \\
\end{array}$ & 434.76 & $\begin{array}{l}9.58 \\
(8.67, \\
10.49) \\
\end{array}$ \\
\hline $\begin{array}{l}\text { Sensitivity } \\
\text { Analysis } 4\end{array}$ & 725.25 & $\begin{array}{l}-9.07 \\
(-9.67,- \\
8.47)\end{array}$ & 702.97 & $\begin{array}{l}-30.64 \\
(-31.18,- \\
30.11)\end{array}$ & 632.20 & $\begin{array}{l}-98.44 \\
(-99.29 \\
-97.58)\end{array}$ & 512.28 & $\begin{array}{l}-215.81 \\
(-216.87, \\
-214.76)\end{array}$ \\
\hline
\end{tabular}

$3{ }^{1}$ Average shingles cumulative incidence with chickenpox vaccination per 100,000 person-years (averaged over 30 or

4 more model runs).

$5{ }^{2}$ Change in shingles cumulative incidence per 100,000 person-years calculated as the average shingles incidence

6 with chickenpox vaccination minus the average shingles incidence without chickenpox vaccination. Positive number

7 represents an increase in cumulative incidence and negative number - a decrease.

$8{ }^{3}$ Sensitivity Analysis 1 - One-dose vaccination schedule; Sensitivity Analysis 2 - Lower coverage rates; Sensitivity

9 Analysis 3 - Higher coverage rates; Sensitivity Analysis 4 - Removing biological effect of boosting.

$10{ }^{4}$ Using Mann-Whitney $U$ test all changes in cumulative incidence for every time and scenario combination were

11 statistically significant $(\mathrm{p}<0.05)$.

12 